\title{
Local Government Debt Limit: Forecast and Management
}

\author{
Keliang Chen \\ School of Economics, Jinan University, Guangzhou, China \\ Email: chan20190225@126.com
}

How to cite this paper: Chen, K.L. (2019) Local Government Debt Limit: Forecast and Management. Modern Economy, 10, 962-972.

https://doi.org/10.4236/me.2019.103064

Received: February 25, 2019

Accepted: March 22, 2019

Published: March 25, 2019

Copyright $\odot 2019$ by author(s) and Scientific Research Publishing Inc. This work is licensed under the Creative Commons Attribution International License (CC BY 4.0).

http://creativecommons.org/licenses/by/4.0/

\begin{abstract}
This paper uses the method of Zsg-dea to measure the debt limit of 31 regions of China in 2017 years. Through 3 iterations and adjustments, it is concluded that 31 regions have reached the optimal debt limit adjustment of DEA effective, and found that there is obvious regional nature of the limit adjustment in various provinces. The regional increase in northeast and northwest China is relatively small, under 30 billion, and then Guangdong, Jiangsu, Shandong, Zhejiang and other coastal cities with better economic development, the debt adjustment is relatively large, in more than 80 billion. At the same time, Guizhou, Liaoning due to the low borrowing efficiency, the reduction is relatively large, there is a debt risk. This paper further puts forward some suggestions on the reform of China's debt limit management system, which provides some reference value for the future reform of the financial system.
\end{abstract}

\section{Keywords}

Zsg-Dea, Debt Limit, Local Government Debt

\section{Introduction}

\subsection{Research Background}

Since 1994, our Government has implemented the Tax Division reform, reclassified the central and local income and expenditure authority, and implemented a self-supporting, self-balancing financial management system, which stipulates that the central government shares most of the tax share. A small amount of money is left to local governments for infrastructure construction and urban development. At the time of the global economic downturn in the 2008 financial crisis, the country released 4 trillion of its investment plans, mainly from local budgets, central government bonds, policy loans, corporate (corporate) bonds and medium-term notes, bank loans and attracting private investment. In 4 tril- 
lion of the investment, local governments have to bear more than $70 \%$ of the investment share, the excessive expansion of power and the compression of financial power have forced local governments to seek other ways of financing. Local government debt has become a common phenomenon in provincial governments at the subnational level.

In October 2011, the Ministry of Finance issued the notice "2011 Local government self-issued debt pilot measures", carrying out local government self-issued debt pilot in Shanghai, Zhejiang Province, Guangdong Province and Shenzhen, the scale cannot exceed the limit approved by the State Council, by the Ministry of Finance agent debt service. The "measures" has opened the way for local governments to send their own debt, and has imposed a total limit on the issuance of debt in the pilot areas. In 2015, the new budget law was formally implemented, giving local governments the right to distribute local government bonds moderately from the legal level. To further guide the issuance of local governments' bonds, the Ministry of Finance issued a number of guidance documents, for example, in December 2015, the opinion of the Ministry of Finance on the implementation of quota management of local government debt requires the effective strengthening of local government debt limit management, the establishment and improvement of local government debt risk prevention and control mechanism, and the proper handling of stock business. The "opinion" once again emphasizes the importance of quota management of local government borrowing, which can serve to dispose of stock debt and limit new debt by imposing quota management on local governments. Since 2010, the balance of local government debt in China has been 10.71 trillion, and by November 2018, the size of local debt grew to 18.29 trillion, an increase of $70.77 \%$, achieving an average annual growth of $8.8 \%$, exceeding GDP growth. At a time when China's current economy is entering a shift period, structural optimization transformation, GDP is shifting from high growth to high-speed growth; high-growth government debt is often accompanied by higher risks, which forces us to pay attention to the limit management of local government borrowing.

\subsection{Research Significance}

The significance of this paper is how to calculate the debt risk of local government and the optimal amount of borrowing by scientific and appropriate methods. Through the factor analysis method, the debt risk of each province under the perfect debt chain is analyzed, and the Zsg-dea model is established, and the government debt limit under the optimal output efficiency is obtained by using reasonable input, output and influence index. It provides effective suggestions for the implementation of different debt limit management in different provinces in China, and has positive significance for the reform of debt limit management system in China in the future.

\subsection{Structural Arrangements}

Part I: Introduction, introduces the research background, research significance, 
hierarchical structure and innovation of this paper.

Part II: literature review, combing the domestic research on local government debt limit literature.

Part III: the choice of empirical model, the selection of indicators and data sources.

Part IV: Empirical results and related analysis.

Part V: Policy recommendations of this paper.

\subsection{Innovation}

From the perspective of research, this paper selects the latest data of local government liabilities, and breaks through the current method of local government debt distribution based on incremental quota, takes the social efficiency of borrowing as a new breakthrough, measures the limit of local government debt, and obtains the amount of debt that each region can borrow when it is optimal social efficiency.

\section{Literature Review}

At present, the research on quota management in China is not enough, most of them stay in the stage of theoretical analysis, Yingqiu Liu [1] through the empirical analysis of the EU, concluded that the full equilibrium deficit rate is 3.5\%, the maximum limit is $5.5 \%$, and the full equilibrium debt rate should be $30 \%$ $35 \%$ as the control target, with a ceiling of $58 \%$. Weitao Diao [2] estimates the general debt limit and the special debt limit in local government debt through the portion of local government fund income and local public revenue, and he believes that the current debt of local governments with repayment responsibilities has exceeded the sum of the limits of general debt and earmarked debt, It is therefore necessary to reduce the size of the debt by disposing of government assets, to ensure the rigid implementation of the debt limit after the implementation of the "new rules" of local debt. Entao Ma [3] analyzes the necessity, existing problems and quota index of current debt limit management in China, puts forward the direction to be considered in the design of the debt limit index, and sets the debt balance, the debt burden rate, the debt rate, the gold rule, the debt rate in the area of infrastructure construction and other 6 indicators. In the empirical analysis, Fan Zhong [4] measured the risk and performance of local government debt, divided the country into a comprehensive risk of higher, high performance of the region; higher comprehensive risk, Use of areas with lower performance; combination of lower risk and higher performance in areas; lower combined risk and lower performance. Feng Wang [5] using the ZSG-DEA models, calculates the efficiency of the use of local government debt in various provinces of the country, and distributes the limits of local government debt in provincial and municipal governments under the principle of optimal efficiency and total quantity.

To sum up, the current research on the local government debt limit of the 
pure theoretical analysis appears to be general and practical difficulties, some of the research link the empirical measurement of the total debt limit and the actual, but there is still imperfect place in the specific indicators and treatment. Based on the study of the debt limit of various provinces, this paper discusses the efficiency of debt use in various provinces, and divides the government debt management mode under different debt tolerance. This can provide a good practical value for the actual operation of government limits.

\section{Research Model, Indicator Selection and Data Source}

\subsection{A Model of Government Debt Limit}

DEA is the method to evaluate the efficiency of multi-input and multi-output decision units, the core idea is to use input-output data to map the boundary of maximum output or minimum input, so as to achieve optimal efficiency. The DEA model assumes that the input-output of each decision-making unit is independent of each other, that the output change of one decision unit does not affect the output changes of other units, or that the input to one decision unit does not affect the input to other variables. However, in the process of studying government debt, there is a limit requirement for local government debt in the People's Congress, which leads to the relationship between input and output variables is not independent. Under the condition that the total input or output is a constant, a decision unit must have one or more other decision units corresponding to increase input or output, so that the total amount is maintained at a balanced value in order to improve efficiency and reduce input or increase output. Because the variables are assumed to be independent of each other in the traditional DEA model, the adjustment is bound to break through the established limit of the total quantity, so the Zsg-dea is introduced for this situation. Zsg-dea is proposed by Lins and Gomes (2003) and belongs to the modified DEA model which must guarantee the total amount unchanged. The Zsg-dea model is divided into input type and output type, the input type Zsg-dea refers to the change of the input of each decision unit, the input change of each decision unit is related to the input change of other decision units, and the input volume of other decision units increases or decreases in order to achieve the reduction or increase of their own input amount, Finally reached the DEA's production possibilities on the boundary. The output type Zsg-dea refers to the change in the output of each decision unit, the output change of each decision unit is linked to the output change of other decision units, and the output of other decision units increases or decreases to achieve the reduction or increase of their own output, and ultimately reaches the boundary of the DEA's production possibilities. Because the research is the debt limit, that is, the input variable amount of change, and the output index selection is fixed can not be changed, so this paper chooses the input-oriented Zsg-dea model.

If the initial efficiency of the decision unit $\mathrm{DMU}_{0}$ is Phi and non-DEA is effective, the decision unit must reduce the use of inputs, reduce the amount of 
$Z_{0} X_{0 k}\left(1-\varphi_{0}\right)$, and at the same time distribute it to other decision units, and the allocation of the decision unit Dmui from $\mathrm{DMU}_{0}$ is:

$$
L_{i k}=\frac{X_{i k}}{\sum_{i \neq 0} X_{i k}} X_{0 k}\left(1-\varnothing_{0}\right) i=1,2,3 \ldots, N
$$

Because all decision units are being adjusted at the same time, one decision unit will receive the allocation of the remaining other decision units, so at the end of the adjustment dmui the amount of input redistribution is:

$$
X_{i k}=\sum_{0 \neq i}\left[\frac{X_{i k}}{\sum_{0 \neq i} X_{i k}} X_{0 k}\left(1-\varnothing_{0}\right)\right]-X_{i k}\left(1-\varnothing_{I}\right) i=1,2,3, \ldots, N
$$

According to the proportional reduction strategy, the input-oriented Zsg-dea model for the relative efficiency evaluation of the decision Unit is:

$$
\begin{gathered}
\min \varnothing_{0} \\
\text { s.t. }\left\{\begin{array}{c}
\sum_{i=1}^{n} y_{i j} \lambda_{i} \geq y_{0 j}, j=1,2,3, \ldots, M \\
\sum_{i=1}^{n} x_{i k} \lambda_{i} \leq x_{0 k}, k=1,2,3 \ldots, R \\
\sum_{i=1}^{i=1} x_{i k} \lambda_{i}\left[1+\frac{X_{0 k}\left(1-\varnothing_{o}\right)}{\sum_{i \neq 0} X_{i k}}\right] \leq \varnothing_{0} X_{0 k} \\
\sum_{i=1}^{n} \lambda_{i}=1, i=1,2,3, \ldots, N \\
\lambda_{i} \geq 0, i=1,2,3, \ldots, N
\end{array}\right\}
\end{gathered}
$$

In this model, all decision units reach the boundary of production probability because of the mutual change of input, that is, the efficiency is optimal.

\subsection{Selection of Indicators}

According to the model and actual situation, the input index selects the debt that the local government has the repayment responsibility in 2017. The categories of local government debt in China are divided into three, namely, the debt for which the Government has the responsibility to repay, the debt for which the Government has the guarantee responsibility and the debt that is liable for relief. A government with a guarantee responsibility and a debt of relief is less likely to require government repayment in the future. After 2015, local governments no longer allow security commitments to provide debt to institutions, which eliminates the target of debt for which governments have security responsibilities. At the same time from the past years of debt share we can find that as of 2010, the Government may bear a certain amount of relief responsibility of other related debts of $1,669,566,000,000$ yuan, accounting for $15.58 \%$, as of 2013 , the Government may bear a certain degree of relief responsibility of other related debt of $4,068,431,000,000$ yuan, accounting for $24.28 \%$, Is far below the government's share of the debt with repayment responsibilities. Starting from the feasibility and stability of debt service, this paper selects the debt of local government with repayment responsibility as input index in 2017. 
In the selection of output index, from the announcement of the results of the government debt audit published by the provincial and municipal audit offices in 2014, we can see that in the 2013, the local government debt expenditure category, municipal construction accounted for $37.49 \%$, land storage accounted for $16.69 \%$, transport facilities construction accounted for $13.78 \%$, Affordable housing 6.77\%, UNESCO 4.82\%, Agroforestry Water Conservancy construction $4.03 \%$, ecological construction and environmental protection $3.18 \%$, industry and Energy $1.21 \%$, other accounted for $12.01 \%$. So we find that the output variables play a decisive role in the five categories of municipal construction, land storage, transport facilities, science, education and agriculture, forestry Water Conservancy.

According to these five categories, this paper selects the urban road length, the quantity of public transport, the area of land expropriation, the mileage of railway business, the mileage of high-speed grade highway, the average number of students in primary and secondary The number of students in higher education, the number of beds in health facilities per million people, the area of soil erosion control, rural electricity generation.

In terms of impact indicators, we have set local GDP, local population density, degree of marketization, degree of fiscal decentralization and debt contribution rate. Showing in Table 1.

At the same time, the total debt of this paper is limited to the provinces and cities approved by the People's Congress in 2017, so that the total debt of the provinces and cities in 2017 is controlled within the debt limit set by the NPC. Second, the amount of debt in each province in 2017 was acquiesced in the amount that could be best developed in the province. Therefore, the total amount

Table 1. Input-Output indicators.

\begin{tabular}{|c|c|c|c|}
\hline Input index & & Output index & Impact indicator \\
\hline \multirow{9}{*}{$\begin{array}{l}\text { Local government } \\
\text { debt with repayment } \\
\text { responsibilities in } \\
2017\end{array}$} & & Length of urban roads (million $\mathrm{km}$ ) & GDP \\
\hline & $\begin{array}{l}\text { Municipal } \\
\text { construction }\end{array}$ & $\begin{array}{l}\text { Number of public transport } \\
\text { (per million people) }\end{array}$ & $\begin{array}{l}\text { Local population } \\
\text { density }\end{array}$ \\
\hline & Land storage & Land expropriation Area & $\begin{array}{c}\text { Degree of } \\
\text { marketization }\end{array}$ \\
\hline & education & $\begin{array}{c}\text { Average number of students in primary } \\
\text { and secondary schools }\end{array}$ & $\begin{array}{l}\text { Degree of fiscal } \\
\text { decentralization }\end{array}$ \\
\hline & & $\begin{array}{c}\text { Number of school students in higher } \\
\text { education }\end{array}$ & $\begin{array}{l}\text { Debt contribution } \\
\text { rate }\end{array}$ \\
\hline & Health & $\begin{array}{l}\text { Number of beds in health facilities } \\
\text { (per million people) }\end{array}$ & \\
\hline & $\begin{array}{l}\text { Agroforestry } \\
\text { Water }\end{array}$ & Rural electricity generation & \\
\hline & Conservancy & Soil erosion Control Area & \\
\hline & Transportation & $\begin{array}{l}\text { Railway Business mileage } \\
\text { High speed grade highway mileage }\end{array}$ & \\
\hline
\end{tabular}


maintained by the following studies is unchanged in order to generate the total amount of debt.

\subsection{Data Sources}

The debts for which local governments were reimbursed in 2017 came from the Ministry of Finance and provincial finance ministries, the length of urban roads (thousands of kilometres), the number of public transport (per million people), the area under land expropriation ( $\mathrm{sq} \mathrm{km}$ ), the average number of school students in primary and secondary schools (million), the number of pupils in higher education (million), Data on the number of beds in health facilities (per million people), soil erosion control area (thousands of hectares), rural electricity generation (million $\mathrm{kwh}$ ), railway mileage (million $\mathrm{km}$ ), high-speed grade road mileage (million $\mathrm{km}$ ), local gross national product, degree of fiscal decentralization, degree of marketization, local population density are derived from statistics from the National Statistical Office, Data on debt contribution rates are calculated from the statistics of the regional finance departments.

\section{Analysis Results and Explanations}

\subsection{Analysis Result}

As can be seen from the table below, in 2017, Jiangsu province's debt line ranked first, the debt balance reached 1.2026 trillion yuan, Shandong province and Guangdong province with 1.0196 trillion yuan and 902.3 billion yuan respectively ranked second and third place. Ningxia Hui Autonomous Region, Qinghai Province, Hainan Province three regions with 122.6 billion yuan, 151.2 billion yuan, 171.9 billion yuan in the countdown to three. Showing in Table 2.

Table 2. Iterations and adjustments.

\begin{tabular}{cccccccccc}
\hline & \multicolumn{2}{c}{ Initial value } & \multicolumn{2}{c}{ First iteration } & \multicolumn{2}{c}{ Second iteration } & Third Iteration \\
\hline Area & Debt & Efficiency & Debt & $\Phi$ & Debt & $\Phi$ & Debt & $\Phi$ \\
\hline beijing & $38,768,800$ & 1 & $42,022,904$ & 1 & $42,239,630$ & 1 & $42,240,500$ & 1 \\
tianjin & $34,239,836$ & 0.8459692 & $31,727,408$ & 0.9866127 & $31,457,930$ & 0.9999336 & $31,456,450$ & 1 \\
hebei & $61,509,700$ & 1 & $66,672,587$ & 1 & $67,016,440$ & 1 & $67,017,820$ & 1 \\
shanxi & $25,785,600$ & 1 & $27,949,944$ & 1 & $28,094,090$ & 1 & $28,094,670$ & 1 \\
neimeng & $61,553,682$ & 1 & $66,720,261$ & 1 & $67,064,360$ & 1 & $67,065,740$ & 1 \\
liaoning & $84,550,000$ & 0.5527238 & $51,775,230$ & 0.9581251 & $49,803,540$ & 0.9998351 & $49,796,100$ & 1 \\
jilim & $31,932,700$ & 1 & $34,613,008$ & 1 & $34,791,520$ & 1 & $34,792,240$ & 1 \\
heilongjiang & $34,546,000$ & 1 & $37,445,658$ & 1 & $37,638,780$ & 1 & $37,639,560$ & 1 \\
shanghai & $46,942,000$ & 0.4148857 & $22,606,850$ & 0.9190201 & $20,867,170$ & 0.9996468 & $20,860,140$ & 1 \\
jiangsu & $120,262,800$ & 1 & $130,335,140$ & 1 & $130,670,500$ & 1 & $130,673,200$ & 1 \\
zhejiang & $92,390,900$ & 1 & $100,145,836$ & 1 & $100,515,700$ & 1 & $100,517,800$ & 1 \\
anhui & $58,233,592$ & 1 & $63,121,495$ & 1 & $63,447,030$ & 1 & $63,448,340$ & 1 \\
\hline
\end{tabular}




\begin{tabular}{|c|c|c|c|c|c|c|c|c|}
\hline Continued & & & & & & & & \\
\hline fujian & $54,627,539$ & 1 & $59,212,764$ & 1 & $59,518,140$ & 1 & $59,519,370$ & 1 \\
\hline jiangxi & $42,690,800$ & 1 & $46,274,101$ & 1 & $46,512,750$ & 1 & $46,513,710$ & 1 \\
\hline shandong & $101,968,000$ & 1 & $110,529,487$ & 1 & $111,572,500$ & 1 & $111,574,800$ & 1 \\
\hline henan & $45,484,730$ & 1 & $49,302,543$ & 1 & $49,556,810$ & 1 & $49,557,830$ & 1 \\
\hline hubei & $57,155,337$ & 1 & $61,952,736$ & 1 & $62,272,250$ & 1 & $62,273,530$ & 1 \\
\hline Hunan & $77,557,000$ & 0.8350558 & $70,639,659$ & 0.9863237 & $769,994,450$ & 0.999937 & $69,991,290$ & 1 \\
\hline Guangdong & $90,233,700$ & 1 & $97,807,569$ & 1 & $98,311,990$ & 1 & $98,314,020$ & 1 \\
\hline Guangxi & $48,168,000$ & 1 & $52,211,036$ & 1 & $52,480,300$ & 1 & $52,481,380$ & 1 \\
\hline Hainan & $17,192,600$ & 0.6854616 & $13,170,697$ & 0.966923 & $12,799,450$ & 0.9998336 & 6 12,797,570 & 1 \\
\hline Chongqing & $40,185,000$ & 1 & $43,557,974$ & 1 & $43,782,620$ & 1 & $43,783,520$ & 1 \\
\hline Sichuan & $84,970,000$ & 1 & $92,102,054$ & 1 & $92,577,050$ & 1 & $92,578,960$ & 1 \\
\hline Guizhou & $86,071,500$ & 0.5011928 & $47,986,350$ & 0.9496832 & $45,746,580$ & 0.9998079 & 45738480 & 1 \\
\hline Yunnan & $67,368,000$ & 1 & $73,022,610$ & 1 & $73,399,210$ & 1 & $73,400,720$ & 1 \\
\hline Xizang & 986,400 & 1 & $1,069,194.61$ & 1 & $1,074,709$ & 1 & $1,074,731$ & 1 \\
\hline Shannxi & $53,954,300$ & 1 & $58,483,016$ & 1 & $58,784,630$ & 1 & $58,785,840$ & 1 \\
\hline Gansu & $20,686,000$ & 1 & $22,422,303$ & 1 & $22,537,940$ & 1 & $22,538,400$ & 1 \\
\hline Qinghai & $15,125,700$ & 1 & $16,395,293$ & 1 & $16,479,850$ & 1 & $16,480,190$ & 1 \\
\hline Ningxia & $12,262,635$ & 1 & $13,291,913$ & 1 & $13,360,460$ & 1 & $13,360,740$ & 1 \\
\hline xinjiang & $33,778,411$ & 1 & $36,613,641$ & 1 & $36,802,470$ & 1 & $36,803,230$ & 1 \\
\hline
\end{tabular}

In the original DEA data, we found that for the first time, 25 of the 31 regions had DEA efficiency of 1 , and the efficiency of 6 regions in Tianjin, Liaoning, Shanghai, Hunan, Hainan and Guizhou was $0.84,0.55,0.41,0.83,0.68,0.5$, of which Guizhou and Shanghai have the lowest initial efficiency. After three iterations, the efficiency values of the 31 regions have reached the optimal DEA efficiency.

\subsection{Data Processing}

We sort the debt adjustments for 31 regions, as shown in the following Table 3.

From the table above, we can see that in the ranking of debt limit adjustment, Jiangsu province ranks first with 104.1 billion debt increase, and Shandong province, Zhejiang province and Guangdong province ranked second to fourth in 96 billion yuan, 81.2 billion yuan and 80.8 billion yuan. It shows that they can appropriately increase their borrowing at the level of the existing debt, and there is still room for greater economic efficiency in borrowing. At the same time, in terms of debt reduction, Guizhou Province, Liaoning Province, Shanghai three regions with 403.3 billion yuan, 347.5 billion yuan, 260.8 billion yuan debt adjustment ranking of the top three, indicating that they need to build on the existing debt to reduce the size of borrowing will reach the level of economic efficiency. 
Table 3. Ranking of 31 local government debt adjustment in China.

\begin{tabular}{cccccc}
\hline Area & Adjustment & Ranking & Area & Adjustment & Ranking \\
\hline Jiangsu & $10,410,400$ & 1 & Beijing & $3,471,700$ & 17 \\
Shandong & $9,606,800$ & 2 & Heilongjiang & $3,093,560$ & 18 \\
Zhejiang & $8,126,900$ & 3 & Xinjiang & $3,024,819$ & 19 \\
Guangdong & $8,080,320$ & 4 & Jilin & $2,859,540$ & 20 \\
Sichuan & $7,608,960$ & 5 & Shanxi & $2,309,070$ & 21 \\
Yunnan & $6,032,720$ & 6 & Gansu & $1,852,400$ & 22 \\
Neimeng & $5,512,058$ & 7 & Qinghai & $1,354,490$ & 23 \\
Hebei & $5,508,120$ & 8 & Ningxia & $1,098,105$ & 24 \\
Anhui & $5,214,748$ & 9 & Xizang & 88,331 & 25 \\
Hubei & $5,118,193$ & 10 & Tianjin & $-2,783,386$ & 26 \\
Fujian & $4,891,831$ & 11 & Hainna & $-4,395,030$ & 27 \\
Shannxi & $4,831,540$ & 12 & Hunan & $-7,565,710$ & 28 \\
Guangxi & $4,313,380$ & 13 & Shanghai & $-26,081,860$ & 29 \\
Henan & $4,073,100$ & 14 & Liaoning & $-34,753,900$ & 30 \\
Jiangxi & $3,822,910$ & 15 & Guizhou & $-40,333,020$ & 31 \\
Chongqing & $3,598,520$ & 16 & & & \\
\hline & & & & & \\
\hline
\end{tabular}

At the same time, the regional adjustments to the provinces and municipalities are divided, as shown in Table 4.

\subsection{Data Analysis}

For the analysis of the above data, there are three provinces in south China, Guangdong, Guangxi and Hainan Province, of which the debt limit of Guangdong and Guangxi provinces has increased, at 80.803 billion yuan and 43.134 billion yuan respectively, and the debt limit of Hainan Province needs to be reduced to 43.95 billion yuan. In north China there are five provinces, of which Beijing, Hebei Province, Shanxi province, Inner Mongolia Autonomous Region four places debt limit for the increase, and then Tianjin's debt limit reduced by 27.834 billion yuan. From the East China region, only Shanghai's debt needs to be reduced to 260.819 billion yuan, the remaining six provinces of the debt limit for the increase, of which Jiangsu province's debt increase is the largest, reached 104.104 billion yuan. The debt limits of the five provinces of the Northwest Territories need to be increased, but the increase is generally at relatively low levels. Three northeastern provinces only Liaoning province needs to carry out debt reduction, the amount reached 347.539 billion yuan, Jilin Province and Heilongjiang province need to increase 28.595 billion yuan and 30.935 billion yuan respectively. In central China, Hunan Province needs to carry out debt reduction, at 75.657 billion yuan, and the other two provinces need to increase their debt. In the southwest region, the debt of Guizhou province needs to be reduced, the 
Table 4. Classification of debt adjustments by area.

\begin{tabular}{cccccc}
\hline \multirow{3}{*}{ South } & Guangdong & 808.03 & & Shannxi & 483.15 \\
& Guangxi & 431.34 & & Gansu & 185.24 \\
& Hainna & -439.50 & Northwest & Qinghai & 135.45 \\
& Beijing & 347.17 & & Ningxia & 109.81 \\
& Tianjin & -278.34 & & Xinjiang & 302.48 \\
\multirow{3}{*}{ North } & Hebei & 550.81 & & Liaoning & -3475.39 \\
& Shanxi & 230.91 & Northeast & Jilin & 285.95 \\
& Neimeng & 551.21 & & Heilongjiang & 309.35 \\
& Shanghai & -2608.19 & & Henna & 407.31 \\
& Jiangsu & 1041.04 & Central & Hubei & 511.82 \\
& Zhejiang & 812.69 & & Hunan & -756.57 \\
& Fujian & 489.18 & & Chongqing & 359.85 \\
& Shandong & 960.68 & & Sichuan & 760.89 \\
& Anhui & 521.47 & & Guizhou & -4033.30 \\
& Jiangxi & 382.29 & & Yunnan & 603.27 \\
\hline
\end{tabular}

reduction has reached the maximum value of the country, 403.33 billion yuan, Chongqing debt increased by 35.985 billion yuan, Sichuan province increased 76.089 billion yuan, Yunnan province increased 60.327 billion yuan.

After the analysis of the data in table above, the debt increase in the provinces under 30 billion yuan is Heilongjiang province, Xinjiang Uygur Autonomous Region, Jilin Province, Shanxi Province, Gansu province, Qinghai province, Ningxia Hui Autonomous Region and Tibet Province and other 8 regions, they are part of the economic development in the middle and lower reaches, Mainly concentrated in the Northwest Territories and northeast China. It is explained that it is necessary to increase the amount of debt appropriately for promoting the economic development of these two regions, so as to achieve the best social benefits. The province of debt increase in more than 80 billion yuan mainly concentrated in Guangdong, Jiangsu, Zhejiang, Shandong and other major provinces, the same point is they are all in the coastal cities, the development is relatively rapid, so they can borrow more debt and guarantee repayment under the condition of ensuring optimal efficiency. At the same time, we see that four municipalities, the optimal efficiency increase in Chongqing, Beijing are about 30 billion yuan, belongs to a relatively low level, and the debt adjustment of Tianjin, Shanghai are reduced, which may be due to the output indicators, they are above the production probability curve or near the production probability curve, needs to be low-key increase or substantial reduction in order to achieve optimal debt efficiency. At the same time, the debt reduction of two regions in Liaoning and Guizhou is the highest, which indicates that their debt have already exceeded the optimal debt limit, which is prone to the risk. 


\section{Policy Recommendations}

According to the empirical analysis, we suggested that the allocation mechanism of debt limit should be adapted to local conditions, which introduce the key factors of regional borrowing such as economic benefit and livelihood benefit, and gradually change the distribution mode of debt limit from economic strength to dominant in debt contribution. Transforming the traditional distribution approach is dominated by new debt lines. Areas with high debt contribution rates and debt conversion rates allow for greater borrowing within a reasonable range. In areas with low debt contribution rates and low debt conversion rates, debtbased debt-ceiling management is needed to ensure that the overall debt balance of the region is reduced year by year. Finally, the effect of de-debt risk is achieved.

In the allocation of quota, the interim measures for the administration of debt limit allocation of new local governments put forward the calculation of additional regional limits related to local financial resources, major project expenditure, debt risk factor, debt management performance factors and local application factor increase. The distribution of the overall limit implements the principle of strong and multi-distribution of financial strength, weak and less allocation of financial strength. This distribution method cuts apart the negative correlation between the government's financial resources and the amount of debt; the higher the Government's financial resources are insufficient and unnecessary to borrow, but the government's lower financial resources are less than the full but not necessary conditions for borrowing; and secondly, this standard is more applicable to the absence of debt risk, it is easy to cause Matthew effect. Therefore, in the current process, with gradual refinement and reform of debt limit management, it is necessary to reform the index design of quota and the design of distribution calculation, so as to achieve the quota standard with efficiency as the main principle of distribution.

\section{Conflicts of Interest}

The author declares no conflicts of interest regarding the publication of this paper.

\section{References}

[1] Liu, Y.Q. (2001) On China's Current Deficit Rate and Debt Rate and Its Cordon. Economic Studies, 8, 3-14.

[2] Diao, W.T. (2015) A Study on the General Debt and Special Debt Limit of Local Governments in China from the Perspective of Debt-Servicing Financial Resources. Southwest Finance, 5, 25-27.

[3] Ma, E.T. and Kong, Z.H. (2017) Study on Debt Limit Management of Local Government in China. Financial Studies, 5, 54-63.

[4] Zhong, F. (2017) Research on Local Government Debt Management Based on Risk and Performance Correlation. Financial Studies, 3, 20-32.

[5] Wang, F., Gao, Y., Wan, Z. and Shi, X.T. (2017) Provincial Local Government Debt Limit Allocation-Based on the Optimal Perspective of Efficiency. East China Economic Management, 8, 105-112. 